\title{
GAMBARAN PERKEMBANGAN MOTORIK HALUS PADA BALITA USIA 3-5 TAHUN DI PAUD AL USMAN
}

\author{
Eka Deviany Widyawaty ${ }^{1, a)}$ \\ ${ }^{1)}$ Program Studi D-III Kebidanan, Akademi Kebidanan Wijaya Kusuma Malang \\ ${ }^{\text {a) Email: ekadeviany719@gmail.com }}$
}

\begin{abstract}
Abstrak
Lima tahun pertama kehidupan adalah periode yang paling peka terhadap lingkungan, sehingga balita disebut "Masa Keemasan", "Jendela Peluang" dan "Periode Kritis". Sehingga apabila masa tersebut tidak dimanfaatkan dengan sebaik-baiknya akan mengganggu perkembangan anak balita dan sangat mempengaruhi keberhasilan anak dalam proses pertumbuhan selanjutnya. Tujuan dari penelitian ini adalah untuk mengetahui Gambaran Perkembangan Motorik Halus Pada Balita Usia 3-5 Tahun di PAUD Al-Usman Desa Pelem Desa Kertosono Kecamatan Nganjuk. Jenis penelitian yang digunakan dalam penelitian ini adalah penelitian deskriptif dengan desain penelitian survei deskriptif. Populasi dalam penelitian ini adalah anak usia 3-5 tahun di PAUD Al-Usman yang berjumlah 53 Balita. Metode pengambilan sampel dalam penelitian ini menggunakan simple random sampling, sejumlah 37 responden. Teknik pengumpulan data menggunakan lembar observasi, dengan menggunakan analisis Univariat. Hasil penelitian ini menunjukkan bahwa dari 37 anak usia 3-5 tahun, perkembangan motorik halus 27 anak (73\%), Ragu-ragu 7 anak $(18,1 \%)$ dan menyimpang 3 anak (8,9\%). Berdasarkan uraian di atas dapat disimpulkan bahwa sebagian besar perkembangan motorik halus pada Balita usia 3-5 tahun di PAUD Al-Usman Nganjuk sudah sesuai.
\end{abstract}

Kata Kunci: Perkembangan, Motorik Halus, Balita.

\begin{abstract}
The first five years of life are the most sensitive to the environment, so toddlers are called the "Golden Age", the "Window of Opportunity" and the "Critical Period". So that if this period is not used properly it will interfere with the development of children under five and greatly affect the success of children in the process of further growth. The purpose of this study was to determine the description of fine motor development in toddlers aged 3-5 years at Al-Usman PAUD, Pelem Village, Kertosono Village, Nganjuk District. The type of research used in this research is descriptive research with a descriptive survey research design. The population in this study were children aged 3-5 years in PAUD Al-Usman, totaling 53 toddlers. The sampling method in this study used simple random sampling, a number of 37 respondents. Data collection techniques using observation sheets, using univariate analysis. The results of this study indicate that from 37 children aged 3-5 years, 27 children (73\%), doubtful motor development were 7 children (18.1\%) and 3 children deviated (8.9\%). Based on the description above, it can be concluded that most of the fine motor development in toddlers aged 3-5 years at PAUD AlUsman Nganjuk is appropriate.
\end{abstract}

Keywords: Development, Motoric Smooth, Toddler.

\section{PENDAHULUAN}

Perkembangan serta pertumbuhan anak merupakan saat- saat yang dinantikan oleh orang tua, sebab perkembangan serta pertumbuhan merupakan salah satu penanda memantau kesehatan anak. Dalam perkembangan anak terdiri atas beberapa perkembangan, yaitu perkembangan personal sosial, perkembangan motorik kasar, perkembangan bahasa, perkembangan motorik halus. Motorik halus yaitu aspek yang berhubungan dengan kemampuan anak untuk mengamati sesuatu, melakukan gerakan yang melibatkan bagian-bagian tubuh tertentu saja dan dilakukan otot-otot kecil, 
tetapi memerlukan koordinasi yang cermat. Misalnya kemampuan untuk menggambar, memegang sesuatu benda, dan lain-lain. Kemampuan motorik lembut pada anak bayi umur 3- 4 tahun ialah dapat melukis memakai krayon, memakai alat ataupun benda serta bisa menjiplak bentuk.

Periode penting dalam tumbuh kembang merupakan waktu balita, ialah tiga tahun, dimana pada usia ini perkembangan serta kemajuan sel- sel otak sedang berlangsung, serta menjadi pertumbuhan serabut- serabut saraf serta cabangnya, sehingga tercipta jaringan saraf serta otak yang kompleks, pada waktu inilah pentingnya seorang keluarga membagikan stimulasi secepat mungkin supaya perkembangan anak dapat berkembang secara normal. Jika perkembangan anak tumbuh secara normal, maka akan bisa menjadi generasi penerus yang baik dan siap dalam menjalani kehidupan. Kenyataannya di masyarakat masih sering dijumpai gangguan perkembangan (Kusumaningtyas, 2016).

World Health Organitation (WHO) melaporkan bahwa 5-25\% anak-anak usia prasekolah menderita disfungsi otak minor, termasuk gangguan perkembangan motorik halus. Departemen kesehatan RI melaporkan bahwa 0,4 juta $(16 \%)$ balita Indonesia mengalami gangguan perkembangan, baik perkembangan motorik halus dan kasar, gangguan pendengaran, kecerdasan kurang dan keterlambatan bicara. Sedangkan menurut Dinas Kesehatan Provinsi Jawa Timur sebesar $85.779 \quad(62,02 \%)$ anak usia prasekolah mengalami gangguan perkembangan.

Terdapat beberapa aspek yang pengaruhi perkembangan pada anak yaitu keturunan, neuroendokrin, hubungan interpersonal, tingakat sosial ekonomi, penyakit, bahaya lingkungan, stess pada anak serta dampak media massa. Bagi Hidayat (2008) faktor-faktor yang mempengaruhi perkembangan anak antara lain merupakan aspek henedler, aspek area pranatal serta aspek postnatal yang terdiri dari budaya, sosial ekonomi, nutrisi, iklim atau cuaca, berolahraga atau latihan fisik, posisi anak dalam keluarga, status kesehatan serta aspek hormonal.

Bagi Susilaningrum et al (2013) terdapat dua aspek yang pengaruhi pertumbuhan serta perkembangan anak ialah aspek dalam (genetik serta hormonal) serta aspek eksternal (aspek pranatal, dalam serta postnatal) aspek pranatal mencakup: nutrisi ibu hamil, mekanis atau posisi janin, racun atau zat kimia, penyimpangan endokrin, infeksi penyakit, kelainan imonologi serta psikologis ibu. Aspek intranatal mencakup: riwayat kelahiran yang menimbulkan trauma kepala pada bayi akibatnya menimbulkan kerusakan jaringan otak, seperti tindakan vacum ekstraksi serta forceps, serta aspek postnatal mencakup: zat makanan, penyakit kronis atau kelainan kongenitakl, lingkungan fisik serta kimia, intelektual, obat- obatan, sosial ekonomi, lingkungan pengasuhan, stimulasi serta obat- obatan.

Masa kritis perkembangan dalam lima tahun pertama usia anak perlu mendapatkan perhatian. Perkembangan sangat dipengaruhi oleh lingkungan dan interaksi antara anak dengan orang tua/pengasuh, maka untuk menyiapkan seorang anak menjadi dewasa yang unggul dikemudian hari, diperlukan kerjasama antara keluarga (orang tua, pengasuh anak dan anggota keluarga lainnya), masyarakat, dan tenaga profesional (kesehatan dan pendidikan) dalam menstimulasi dan mendeteksi perkembangan motorik halus pada anak sesuai usia serta penyuluhan-penyuhan tentang perkembangan anak oleh tenaga kesehatan.

Kegiatan deteksi dini pada Balita bertujuan untuk mendeteksi secara dini adanya penyimpangan perkembangan motorik halus sehingga dapat dilakukan stimulasi yang rutin serta intervensi untuk memperbaiki perkembangan motorik halus pada anak bila ditemukan penyimpangan, dilakukan rujukan dini ke fasilitas 
kesehatan apabila penyimpangan tidak dapat diperbaiki atau sesuai indikasi. Deteksi dini dapat dilakukan dengan menggunakan beberapa alat skrining seperti Kuesioner Pra Skrining Perkembangan (KPSP) dan Stimulasi Deteksi Intervensi Dini Tumbuh Kembang (SDIDTK).

Tujuan dalam penelitian ini adalah mengetahui gambaran perkembangan motorik halus pada balita usia 3-5 tahun di PAUD Al-Usman Desa Pelem, Kecamatan Kertosono, Kabupaten Nganjuk.

\section{METODE PENELITIAN}

Jenis penelitian yang digunakan dalam penelitian ini adalah penelitian deskriptif dengan rancangan penelitian survey deskriptif. Populasi dalam penelitian ini adalah balita usia 3-5 tahun di PAUD Al-Usman Desa Pelem Kecamatan Kertosono Kabupaten Nganjuk, Sebanyak 53 Balita. Cara pengambilan sampel dalam penelitian ini menggunakan simple random sampling, sejumlah 37 responden. Teknik pengumpulan data menggunakan lembar observasi, dengan menggunakan analisis Univariate.

\section{HASIL DAN PEMBAHASAN}

Berdasarkan hasil penelitian menunjukan fakta bahwa responden berumur 36-48 bulan sejumlah 23 balita. Sebagian besar responden perkembangan motorik halus sesuai sejumlah 17 balita (74\%) dan sebagian kecil responden perkembangan motorik halus meragukan sejumlah 3 balita (13\%), menyimpang sejumlah 3 balita (13\%).

Tabel 1. Distribusi Frekuensi

Perkembangan Motorik Halus Balita Usia 36-48 bulan

\begin{tabular}{cccc}
\hline No & $\begin{array}{c}\text { Perkembangan } \\
\text { Motorik Halus }\end{array}$ & Jumlah & $\begin{array}{c}\text { Presentase } \\
(\boldsymbol{\%})\end{array}$ \\
\hline 1 & Sesuai & 17 & $74 \%$ \\
\hline 2 & Meragukan & 3 & $13 \%$ \\
\hline 3 & Menyimpang & 3 & $13 \%$ \\
\hline & Total & 23 & $100 \%$ \\
\hline & & &
\end{tabular}

Menurut Depkes (2007), Dalam KPSP pada usia 36-48 bulan balita harusnya sudah bisa mencoret-coret tanpa bantuan atau penunjuk, membuat garis lurus sekurang-kurangnya 2,5 cm, menggambar lingkaran, menumpuk 8 buah kubus, menggunting sesuai pola garis lurus.

Balita usia 36-48 bulan di PAUD AlUsman Desa Pelem Kecamatan Kertosono Kabupaten Nganjuk yang perkembangan motorik halusnya meragukan karena belum bisa membuat garis lurus sepanjang 2,5 cm, menggambar lingkaran dan menyusun 8 buah kubus bisa, dan menyimpang karena belum bisa membuat garis lurus sekurang-kurangnya $2,5 \mathrm{~cm}$, menggambar lingkaran, menumpuk 8 buah kubus, menggunting sesuai pola garis lurus. Dimana kegiatan-kegiatan tersebut merupakan indikator perkembangan motorik halus pada usia 36-48 bulan, maka perlu adanya kerjasama antara guru dan orang tua untuk menstimulasi dini balita dengan perkembangan motorik halus meragukan dan menyimpang agar perkembangannya sesuai tahapan perkembangan pada usianya dan melakukan rujukan dini ke fasilitas kesehatan apabila penyimpangan tidak dapat diperbaiki atau sesuai indikasi.

Tabel 2. Distribusi Frekuensi

Perkembangan Motorik Halus Balita Usia 48-60 bulan

\begin{tabular}{clcc}
\hline No & $\begin{array}{l}\text { Perkembangan } \\
\text { Motorik Halus }\end{array}$ & Jumlah & $\begin{array}{c}\text { Presentase } \\
(\boldsymbol{\%})\end{array}$ \\
\hline 1 & Sesuai & 10 & $71,4 \%$ \\
\hline 2 & Meragukan & 4 & $28,6 \%$ \\
\hline 3 & Menyimpang & 0 & $0 \%$ \\
\hline & Total & 14 & $100 \%$ \\
\hline & & &
\end{tabular}

Berdasarkan hasil penelitian
menunjukan fakta bahwa responden
berumur $48-60$ bulan sejumlah 14 balita.
Sebagian besar responden perkembangan
motorik halus sesuai sejumlah 10 balita
$(71,4 \%)$ dan sebagian kecil responden
perkembangan motorik halus meragukan


sejumlah 3 balita $(28,6 \%)$, menyimpang sejumlah 0 balita $(0 \%)$.

Menurut Depkes (2007), dalam kpsp pada usia 48-60 balita harusnya sudah bisa membuat lingkaran, menumpuk 8 buah kubus, menggunting sesuai pola garis lurus, menggunting zig-zag melengkung, menunjuk garis lurus yang lebih panjang sebanyak 3 kali dan menggambar sesuai contoh tanda tambah (+).

Balita usia 48-60 bulan di PAUD Al Usman Desa Pelem Kecamatan Kertosono Kabupaten Nganjuk Tahun 2017 yang perkembangan motorik halusnya meragukan karena belum bisa menggunting zig-zag melengkung, menunjuk garis lurus yang lebih panjang sebanyak 3 kali dan menggambar sesuai contoh tanda tambah (+). Dimana kegiatan-kegiatan tersebut merupakan indikator perkembangan motorik halus pada usia 48-60 bulan, maka perlu adanya kerjasama antara guru dan orang tua untuk menstimulasi dini balita dengan perkembangan motorik halus meragukan dan menyimpang agar perkembangannya sesuai tahapan perkembangan pada usianya dan melakukan rujukan dini ke fasilitas kesehatan apabila penyimpangan tidak dapat diperbaiki atau sesuai indikasi.

Tabel 3. Distribusi Frekuensi Balita Berdasarkan Perkembangan Motorik Halus Pada Balita Usia 3-5 Tahun

\begin{tabular}{cccc}
\hline No & $\begin{array}{c}\text { Perkembangan } \\
\text { Motorik Halus }\end{array}$ & Jumlah & $\begin{array}{c}\text { Presentase } \\
(\mathbf{\%})\end{array}$ \\
\hline 1 & Sesuai & 27 & $73 \%$ \\
\hline 2 & Meragukan & 7 & $18,9 \%$ \\
\hline 3 & Menyimpang & 3 & $8,1 \%$ \\
\hline & Total & 37 & $100 \%$ \\
\hline
\end{tabular}

\footnotetext{
Berdasarkan hasil penelitian menunjukan fakta bahwa responden berumur 3-5 bulan sejumlah 37 Balita. Sebagian besar responden perkembangan motorik halus sesuai sejumlah 27 Balita (73\%), perkembang responden perkembangan motorik halus meragukan sejumlah 7 balita $(18,9 \%)$ dan sebagian
}

kecil responden perkembangan motorik halus menyimpang sejumlah 3 Balita $(8,1 \%)$.

Menurut Sujiono Bambang (2013), Pada usia 3-5 Tahun Balita harusnya sudah bisa menggambar mengikuti bentuk, menarik garis vertikal, menjiplak bentuk lingkaran, membuka dan menutup kotak, menggunting kertas sesuai pola garis lurus, menggambar sesuatu yang diketahui bukan yang dilihat, menggunting zig-zag, melipat kertas, menggunting sesuai pola, menyusun mainan kontruksi bangunan, mewarnai lebih rapi, meniru tulisan.

Balita usia 3-5 Tahun di PAUD Al Usman Desa Pelem Kecamatan Kertosono Kabupaten Nganjuk Tahun 2017 yang perkembangan motorik halusnya meragukan dan menyimpang karena belum bisa membuat garis lurus sekurangkurangnya $2,5 \mathrm{~cm}$, menggambar lingkaran, menumpuk 8 buah kubus, menggunting sesuai pola garis lurus, menggunting zigzag melengkung, menunjuk garis lurus yang lebih panjang sebanyak 3 kali dan menggambar sesuai contoh tanda tambah (+). Dimana kegiatan-kegiatan tersebut merupakan indikator perkembangan motorik halus pada usia 3-5 tahun, maka perlu adanya kerjasama antara guru dan orang tua untuk menstimulasi dini balita dengan perkembangan motorik halus meragukan dan menyimpang agar perkembangannya sesuai tahapan perkembangan pada usianya dan melakukan rujukan dini ke fasilitas kesehatan apabila penyimpangan tidak dapat diperbaiki atau sesuai indikasi.

Umur dapat mempengaruhi pengetahuan seorang. Bertambahnya umur seorang dapat mempengaruhi pada pertambahan pengetahuan yang diperolehnya, akan tetapi pada umur tertentu ataupun menjelang umur lanjut keahlian mengingat ataupun penerimaan sesuatu pengetahuan akan menurun (Notoatmodjo, 2008). Sedangkan menurut Hurlock (2014) semakin cukup umur, tingkatan kedewasaan serta kekuatan 
seseorang akan lebih matang dalam berfikir serta bekerja.

Stimulasi perkembangan ialah kegiatan merangsang kemampuan dasar anak umur 0- 6 tahun supaya anak dapat berkembang dan bertumbuh secara maksimal (Depkes RI, 2009). Anak yang kurang mendapat stimulasi dapat mengalami penyimpangan tumbuh kembang ataupun bahkan gangguan secara menetap. Stimulasi pada anak dapat dilakukan oleh orang tua, pengasuh, keluarga atau orang-orang yang berada di sekitar anak. Stimulasi yang diberikan dapat berupa verbal, auditori, visual, taktil, dan lainlain (Susanto, 2011). Hasil Khususnya hal ini menunjukkan bahwa orang tua sudah tahu cara melakukan stimulasi kepada anaknya. Dalam perilaku ini dibagi menjadi 3 tahapan umur yaitu 01 tahun, 1-3 tahun dan 4-6 tahun, dari ketiga tahapan umur tersebut $>75 \%$ seluruh orang tua sudah melakukan stimulasi pada anak baik motorik kasar, motorik halus, bahasa dan personal sosial (Haryanti et al., 2019).

Oleh sebab itu orang tua mempunyai peran penting dalam mendorong perkembangan anak karena menjadi orang terdekat untuk anak. Stimulasi yang dilakukan orang tua dalam mendukung perkembangnya ialah stimulasi gerak kasar, stimulasi kemampuan gerak halus, stimulasi kemampuan bicara dan bahasa serta stimulasi kemampuan sosialisasi dan kemandirian (Sulistyawati, 2014).

Orang tua sudah sepatutnya harus mengetahui dan memahami cara-cara menstimulasi perkembangan anak agar dapat mencegah keterlambatan perkembangan. Penting bagi orang tua untuk memahami berbagai faktor yang mempengaruhi perkembangan anak dan melakukan stimulasi perkembangan, khususnya perkembangan bagi anak usia 0-6 tahun dengan meningkatkan pengetahuan mereka dalam memberikan stimulasi (Haryanti, 2019).

\section{KESIMPULAN}

Berdasarkan hasil penelitian dan pembahasan tentang Gambarn Perkembangan Motorik Halus Pada Balita Usia 3-5 Tahun di PAUD Al Usman Desa Pelem Kecamatan Kertosono Kabupaten Nganjuk dapat ditarik kesimpulan bahwa sebagian besar responden memiliki karakteristik perkembangan motorik halus sesuai dengan usianya.

\section{UCAPAN TERIMA KASIH}

Ucapan terima kasih kami ucapkan kepada rekan sejawat, para dosen, dan kepada pihak-pihak yang telah membantu dalam proses penelitian ini sehingga dapat selesai dengan baik dan tepat waktu.

\section{DAFTAR PUSTAKA}

Alimul, A. A. (2008). Pengantar Ilmu Kesehatan Anak Untuk Pendidikan Kebidanan. Jakarta: Penerbit Salemba.

Bambang, S. (2007). Metode Pengembangan Fisik. Jakarta: Pusat Penerbit Universitas Terbuka.

DepKes, R. I. (2010). Pedoman Pelaksanaan Stimulasi, Deteksi dan Intervensi Dini Tumbuh Kembang Anak di Tingkat Pelayanan Kesehatan Dasar. Jakarta: Dep Kes RI.

Haryanti, D., Ashom, K., \& Aeni, Q. (2019). Gambaran Perilaku Orang Tua dalam Stimulasi pada Anak yang Mengalami Keterlambatan Perkembangan Usia 0-6 Tahun. Jurnal Keperawatan Jiwa, 6(2), 64-70.

Hidayat, A. (2014). Metode penelitian kebidanan dan teknik analisis data.

Hurlock, E. B., Istiwidayanti, Sijabat, R. M., \& Soedjarwo. (1990). Psikologi Perkembangan: Suatu Pendekatan 
Sepanjang Rentang Kehidupan. Jakarta: Erlangga.

Kusumaningtyas, K. (2016). Faktor Pendapatan Dan Pendidikan Keluarga Terhadap Perkembangan Motorik Halus Anak Usia 3-4 Tahun. Jurnal Penelitian Kesehatan" SUARA FORIKES"(Journal of Health Research" Forikes Voice"), 7(1).
Notoatmodjo, S. (2007). Pendidikan dan Perilaku Kesehatan. Cetakan 2. Jakarta: Rineka Cipta.

Susanto, M. P. (2011). Perkembangan Anak Usia Dini: Pengantar Dalam Berbagai Aspeknya. Jakarta: Kencana.

Susilaningrum, R., \& Utami, S. (2013). Asuhan keperawatan bayi dan anak.

Sulistyawati, A. (2015). Deteksi tumbuh kembang anak. 